\title{
土木工程施工中裂缝处理方法浅析
}

\author{
梁青原 \\ 广西建工集团第五建筑工程有限责任公司 \\ DOI:10.32629/btr.v2i3.1945
}

[摘 要] 在当前的建筑工程项目中,混凝土材料应用十分广泛,其在工程建设中扮演着十分重要的角色。但就目前实际发展现 状来看, 在土木工程施工中, 经常会出现严重的裂缝问题, 从而对工程建设质量产生影响。本文主要针对这一问题展开了分析和 探讨。

[关键词] 土木工程施工；裂缝；处理方法

在土木工程建设中, 混凝土施工是至关重要的内容, 随 着现代化施工技术水平的不断提升, 混凝土裂缝问题也得到 了有效的控制, 但受到各种因素的影响, 在土木工程施工中, 混凝土裂缝问题仍十分常见, 从而直接导致工程建设质量大 打折扣。鉴于上述情况, 在今后的施工中, 一定要强化对混凝 土裂缝问题的有效控制, 提升工程建设质量, 促进我国建筑 行业的可持续稳定发展。

\section{1 混凝土裂缝概述}

在当前的建筑结构中, 混凝土是至关重要的组成部分, 同时也是现代化工程建设项目中应引起人们重视的施工环 节和内容。在土木工程的混凝土施工中, 通常具有结构厚度 大、工程施工量大和工程条件复杂等特征, 且施工中经常会 面临各种复杂的、不可控的因素。特别是在基础工程中, 在 混凝土施工方面存在着严重的管理隐患和缺陷, 要求相关部 门和人员强化对施工技术和方法的改进, 以此为混凝土施工 质量提供保障。在当前的土木工程混凝土施工中, 最常见的 裂缝问题包括贯穿裂缝、深层混凝土裂缝、表面裂缝等, 针 对于不同的裂缝问题通常要采取针对性的措施加以解决 ${ }^{[1]}$ 。

\section{2 土木工程中混凝土施工裂缝问题的产生原因}

\section{1 施工工艺}

在对混凝土结构进行堆放、运输、制作和浇筑的过程中, 一旦所采取施工工艺不合理, 便会很容产生各种裂缝问题, 具 体如横向裂缝、纵向裂缝、表面裂缝、贯穿裂缝等等。混凝 土结构和受力钢筋保护层较厚, 减小了构件的有效高度, 也会 产生垂直于受力钢筋的裂缝。随着混凝土运输和摚拌时间的 不断延长, 水分会被迅速蒸发, 从而直接降低混凝土的坞落度, 使混凝土出现收缩裂缝问题。此外, 在混凝土初期养护工作中, 若混凝土过于干燥也会产生不规则的裂缝问题, 在百送混凝 土施工环节中, 为确保其流动性, 增加水泥和水用量, 会增加 混凝土凝结硬化时的收缩量, 产生裂缝问题。在对混凝土进行 分层浇筑的过程中, 若工作人员不能妥善处理接头位置, 则在 新、旧混凝土交接的过程中也会产生裂缝问题 ${ }^{[2]}$ 。

\section{2 混凝土质量问题}

混凝土一般是由砂石、水、掺料等共同构成, 这些材料 的质量、数量以及比例等均会对混凝土材料质量产生影响。
若水泥生产与工程建设要求不符合, 则在交货和验收环节也 会很难达到规定标准。在施工现场中, 混凝土材料的存储很 可能会出现受潮的问题, 从而导致砂石质量难以满足工程建 设要求。此外, 在对粗细砂进行应用的过程中, 若工作人员不 能对砂石和石料进行严格控制和篮选, 也会对混凝土应用质 量产生影响, 从而出现各种裂缝问题。此外, 在对水泥材料进 行存放的过程中, 一旦存储时间过长或出现受潮, 也会对水 泥质量产生严重影响, 从而在无形中增加了混凝土裂缝问题 的发生概率 ${ }^{[3]}$ 。

\section{3 混凝土搅拌问题}

在混凝土搅拌环节, 若摚拌质量不达标, 振捣不够均匀 和密实, 还会对浇筑效果产生影响。在入模环节, 若温度达不 到指定标准, 便很容易在施工过程中出现各种裂缝问题。水 泥材料的过快液化将会产生大量热量, 增加裂缝问题的发生 概率。在入料环节, 若温度过高, 将会直接增加混凝土内部温 度, 从而使缝腺问题产生。此外, 在施工过程中, 若施工时机 选择不当、温度不达标等, 将会使混凝土出现拉应力, 导致各 种裂缝问题产生。

\section{4 应力问题}

在混凝土施工过程中, 裂缝问题之所以产生, 一般是由 于次应力、动荷载以及静荷载等共同作用而形成。通过这种 裂缝进行划分, 通常可分为次应力裂缝和直接应力裂缝两种, 前者一般是由于外部荷载的次应力所导致, 后者主要是由外 部荷载直接应力所导致 ${ }^{[4]}$ 。

\section{3 土木工程施工中裂缝处理方法}

3.1 对材料进行优化控制

剪力墙配筋通常比较密实, 为确保混凝土也能够紧密填 充, 通常要对石子最大粒径、粗细集料级配进行优化控制。 若石子粒径较大, 则很容易卡在钢筋和模板之间, 相比于砂 浆, 混凝土的收缩较大, 因此在拆模之后, 很容易使钢筋出现 裂缝问题。在对水泥材料进行选择的过程中, 要尽可能选择 产品质量稳定、生产规模大、信誉良好的大型厂家的水泥材 料, 若材料稳定性不达标, 要禁止将其应用于施工中, 而是要 优先选择低水化热和低收缩的水泥, 否则便很容易出现裂缝 问题。此外, 还要对砂、骨料等的含泥量进行严格控制, 同时 
派遣专业人员对石骨料进行清洗, 如此不仅能够减少泥沙含 量, 同时也能实现对骨料温度的有效控制 ${ }^{[5]}$ 。

\section{2 强化施工工艺控制}

在此过程中, 要对混凝土施工配合比进行严格控制, 结 合混凝土的质量检验标准、强度等级等对配合比进行确定, 同时还要进行严格的监督和管理。在对混凝土进行浇筑的过 程中, 还要实现对振捣工序的严格控制, 以免出现浮浆过多 的问题。此外, 还要强化对混凝土养护的控制, 在完成浇筑后 要进行及时覆盖, 以免水分过快蒸发, 与此同时, 还要尽可能 的缩短养护和浇筑的时间, 确保施工温度适宜, 适度浇水, 如 此不仅能够降低混凝土裂缝问题的发生概率, 同时也能降低 约束应力。

\section{3 严格控制建筑施工}

在对混凝土进行振捣的过程中, 工作人员一般要会结合 混凝土的坍落度对振捣时间进行合理控制。与此同时, 还可 尝试将二次振捣和二次抹面技术应用其中, 快速排出混凝土 内部的水分和气泡。在完成混凝土浇筑后, 需妥善做好覆盖 养护工作, 对于大面积的板类结构或大体积混凝土, 可采取 蓄水养护的方式, 在覆盖养护时, 可选择保水性良好的材料 如草袋、麻袋等进行覆盖, 同时还要由专业人员进行定期巡 查, 以确保混凝土湿度达标, 对混凝土干缩问题进行缓解。二 次压膜技术通常开始于覆盖之前, 以免混凝土出现表面裂缝 问题。在覆盖养护的一周之前, 施工人员通常要进行 24 小时 的浇水养护, 覆盖后一周需结合混凝土湿润度对浇水次数进 行确定, 正常情况下, 应保证每日浇水 7 次左右, 如此能够有 效避免收缩裂缝问题的发生 ${ }^{[6]}$ 。

\section{4 完善施工方案}

对施工方案进行完善, 能够实现对混凝土裂缝问题的有 效控制, 在施工方案中, 通常要对混凝土振捣、混凝土运输、 浇筑时间、浇筑量等进行明确规定。除此之外, 还要对一次 浇筑的厚度进行控制, 同时重点关注水平施工缝位置, 正常 情况下, 都是设置在变截面位置, 远离受拉钢筋位置。在对混 凝土浇筑时间进行确定时, 通常要避开昼夜温差较大的日子 以及炎热干燥的天气。

3.5 对养护标准进行严格执行
混凝土养护的主要目的在于提升强度, 并确保其能够正 常硬化, 免受外界因素的影响。养护的关键在于降低混凝土 的温度, 使之与外界气温相接近, 避免降温过程中出现的温 差问题。最常规化的混凝土养护方法是浇水。对于大体积混 凝土而言, 由于块体的内外部温差较大, 强度增长不一致, 因 此在具体实践中, 要尽可能晚的拆模, 并要及时的进行回填 和覆盖, 以免受到外部气候因素的影响, 结合混凝土强度增 长情况对养护时间进行确定。

总之, 在土木工程施工中, 裂缝问题十分常见, 从而也会 对工程建设质量产生直接影响。为避免上述问题, 在今后施 工中一定要强化对混凝土裂缝问题的控制, 对其裂缝机理进 行深入分析, 如此才能最大限度降低裂缝问题的发生概率, 为工程建设质量提供保障 ${ }^{[7]}$ 。

\section{4 结束语}

综上所述, 裂缝问题在土木工程混凝土施工中尤为常见, 但裂缝问题的控制却是一个系统化、综合化的过程, 要求相 关工作人员综合考虑各方面因素, 强化监督与管理, 从源头 上入手避免混凝土裂缝问题的发生, 从而为土木工程建设质 量提供良好保障, 促进我国建筑行业的可持续稳定发展。

\section{[参考文献]}

[1]刘匡勋, 钟国辉.浅析混凝土结构裂缝处理技术在土 木工程中的应用[J].建材与装饰,2013,(5):170-171.

[2]曾凡奎,胡长明,车佳玲,等.法门寺合十舍利塔震后裂 缝处理技术研究 [ J J . 西安建筑科技大学学报(自然科学 版),2015,40(5):667-671.

[3]李波, 黄秀霞.钢筋混凝土结构裂缝的成因及防控处 理措施的研究[J].西部探矿工程,2013,25(12):786-758.

[4]刘连杰, 张亮亮, 全学友.某车库屋面梁开裂原因鉴定 与新型直剪锚栓钢板加固处理 [J].建筑结构,2017,(15):854-589.

[5]梁力, 夏海江, 王健, 等.参窝水库溢流坝闸墩裂缝加固 处理效果分析[J].现代农业科技,2014,(3):210-211.

[6]张鹏,戴建国,赵铁军,等.带裂缝混凝土的吸水性能及 防水处理的影响[J].建筑材料学报,2016,13(1):740-744.

[7]李强,姜早龙, 李慧民.预应力混凝土箱梁针固端裂缝 成因分析及处理[J].公路工程,2013,38(2):133-136. 